\title{
Crossing the Line: Drawing as Babel Fish
}

Sarah Casey and Gerry Davies, Lancaster University

\begin{abstract}
This article examines the emergence of illustrative practices among fine artists to achieve a particular mobility, one that enables them to gather, synthesize and communicate information across diverse environments, locations and communities. The article recognizes a growing appetite among contemporary illustrators and artists to work collaboratively and across previously separate disciplines, and focuses on artists leaving the studio to seek out ever more responsive applications of drawing. This reveals a hybrid, fluid approach in drawing, a new sensitivity in which drawing is used by artists as a way of analysing, communicating and reflecting upon aspects of lived experience, some of which might normally be the province of other research professionals. We explore how these 'itinerant' artists use drawing to translate into graphic form information, ideas and practices from other fields of activity - for instance, oceanography (Matthews), medicine (Midgley) and political activism (Jill Gibbon). While these contemporary practices are at the cutting edge, we discuss their direct lineage to Ruskin's Elements of Drawing (1857) and his belief in the use of drawing to interrogate the world and our position in it. We argue that this under-acknowledged mode of practice is timely and significant for a globalized interdisciplinary research community because it reveals drawing's capacity to intercede, for problem-solving and for building relationships across otherwise disparate communities and areas of expertise.
\end{abstract}




\section{Drawing as 'Babel Fish'}

Our focus in this article is the emergence among artists of a new type of

observational, communicative drawing that builds on the traditions of illustration. In recent years, illustration has demonstrated capacity to offer itself to opportunities for dialogical practice, engaging with communities, institutions and current affairs (Krummel 2005; Vormittag 2014). The article evaluates further evidence that in art, drawing offers a useful tool for interdisciplinary dialogue, based on drawing's capacity to translate experience from one field to another. This emphasis on translation led to the idea of 'Drawing as Babel Fish', a title taken from a fictional device - the Babel Fish - invented by the late Douglas Adams, author of the Hitchhiker Guide to the Galaxy. The Babel Fish is a tool for intergalactic translation between creatures who otherwise could not communicate with each other. Our idea is that drawing, like the Babel Fish, is a small, portable, universal mode of translation.

This association arises from the long-valued quality drawing to translate sense experience from one realm to another, and thus the translation of touch, motion and space into graphic forms and also acts of language translation - hence Babel Fish whether the changes made to the sentence are correct.

- across the disciplines of illustration and fine art, and, as importantly, potential new relationships between drawings and wholly non art activities. 
Our discussion addresses a challenge faced by drawing, namely that drawing, once an indispensable tool for observation and analysis across modes of cultural production, has now been principally decoupled from its investigative and communicative role in fine art.

We propose that through drawing on illustration new ways of drawing in fine art have become possible.

As technologies assumed the role of depictive illustration in the sciences, in the latter half of the twentieth century the arts witnessed a drive towards evermore individualistic ways of drawing. Markets and modernist endgames have both, in their own way, encouraged artists to compete to make their practices more spectacular or distinctive, to come up with work that is ground-breaking or boundary-busting for the sake of it (Currie 2007: n.p.). Equally, the postmodern embrace of image reappropriation and decline of teaching of drawing in British art schools have undoubtedly contributed to the decoupling of drawing from its investigative role. And where drawing and observation may have once been commonly used outside the studio with groups and communities, today we see an increase of relational practices such as artist residencies, community co-creation and participatory art that foreground performativity and intervention over the studied examination.

This appears to be a growing area of research strength in illustration - for instance, Louise Vormittag's recent work, particularly that with the Renal Ward at Royal London Hospital (2014). Artists such as Jessie Brennan have also used drawing to gather narratives form residents of a housing block in tower hamlets threatened 
with demolition (Neville 2015), a project that recalls the approach of Mitch Miller whose illustration gathers the stories of place from communities (2013). Yet there is a gathering evidence of a small number of fine artists adopting forms of drawing that do initiate conversations but as a means of investigating the world to translate information from one realm of experience to another.

Among fine artists, applications of drawing have emerged that are doing something distinctly different, from these examples cited above. For instance, transcribing the motions of the sea, exposing arms fairs and assisting medical advances. While seemingly unrelated, on closer inspection, what unites them is that they are going out into unfamiliar environments and using drawing to investigate, understand and enter into exchange with other research professionals outside the creative arts - for example, ecologists and medics. What is interesting about these practices is their appropriation and adaption of illustrative practice as a means to traverse boundaries between areas of professional expertise to communicate information and experience across otherwise distinct communities. These artists and investigations are not driven or constrained by a brief but by research questions. Consequently, they point towards a renewed potential for forms of drawing that are depictive and dialogical to be valuable tools for interdisciplinary research.

We should clarify that what we mean by 'dialogical' here are reflexive practices, ones with recursive features enabling the artist to enter into a relationship, to be affected. This is different to drawing's use with participants in projects, workshops and social projects as mentioned above, which have iterative relationships with the

Comment [K6]: Please confirm the accuracy of changes made to the sentence. 
human participants. What we are describing is a drawing encounter with a context, institution, community or environment in which the artist opens themselves up to the environment, as a weather vane or litmus paper, absorbent and responsive to its conditions, free of restrictive preconceived ideas or needs.

While examples of these practices remain a disparate minority, we believe it is fruitful to bring these examples together to reconsider the usefulness of drawing in the contemporary context by asking the following questions:

- How are different modes of observational drawing used by contemporary artists used to translate experience into information and from one field to another?

- How might drawing enter meaningful dialogue with disciplines and activities outside the creative arts?

- What are the benefits of using drawing in this way?

We begin to address these questions by taking an overview of the qualities and characteristics of drawing that lend it to investigation, communication and working onsite with different communities. We focus on a group of contemporary British artists with 'illustrative' practices, and then examine the drawing of select individual artists as case studies to identify approaches, shared practices and linking themes. These examples are then situated in the context of historical precedents of drawing as a dialogical and investigative praxis. The case studies are then evaluated 
collectively to understand the different ways in which drawing acts as a device for translating and communicating experience, and to explore the capacity for drawing to effect translation and initiate dialogue. Given the emphasis on interdisciplinary, collaborative and community working, this exploration is valuable and timely. We believe there is significant potential in this type of drawing to disrupt established ways of thinking within the disciplines that it engages with and effect change in drawing itself.

\section{The qualities of drawing}

As artists and illustrators in the twenty-first century, in which the digital is paramount, we may ask why should drawing matter? Ultimately, it is a question of agency. Drawing is an active instrument controlled and guided by a reflective and critical agent. As such it captures more than data, appearances or even visual qualities. The drawer can adapt and respond moment by moment in relation to a changing context. Drawing has an ability to observe, measure, record and communicate phenomena and experiences where other technologies fail.

For example, a photographer may adjust camera settings to accommodate technical challenges; a drawer can change an entire drawing language encompassing conceptual shifts and the adoption of new means, new ideas from related and different fields. This enables the user to observe, measure, record and communicate through drawing phenomena and multi-sensory experiences that other technologies cannot (Cajal 1999: 113; Lyons 2009). The capacity to subjectively edit, select and emphasize visual information is drawing's strength.

Comment [K8]: Please confirm the accuracy of changes made to the sentence. 
Furthermore, drawing's immediacy and economy enables it to, as it were, speak clearly. Its linearity can identify and demarcate boundaries, edges and features, and a single line, used continuously or with a vocabulary of dots and dashes, can often attaint the clarity of a script.

This is illustration's great success; it is for these reasons that illustration is used to illuminate, to make clear and as a device for communication.

That its materials are normally dry and monochrome, portable and low cost makes drawing an accessible technology. While these factors undoubtedly encourage artists to use drawing promiscuously, experimentally and without weight of expectation or fear of expense, they also enable drawing to bridge boundaries between diverse subjects, and its ubiquity in everyday life offers potential to span academic discourse and community experience. Similarly, illustration has been described as the 'connective tissue' bridging different disciplines (McCannon 2014).

Over the past fifteen years there has been an increased visibility of drawing through survey exhibitions and publications. These have either sought to demonstrate the vitality of drawing generally (Kovats 2007; Hoptman 2002) or define the material, aesthetic and theoretical characteristics of the discipline (Kingston 2003; Nancy 2013; Sawdon and Marshall 2012). However, there has been little comprehensive attempt to question the contribution of drawing to knowledge in both cognate and distant disciplines (Casey and Davies 2012). This article is one of a number of recent publications in which the authors seek to redress this lacuna. So rather than asking

Comment [K10]: The publication year of Kingston (2005) has been changed to match the publication year Kingston (2003) given in the reference list. Please confirm whether this is correct.

Comment [K11]: The publication year of Nancy (2012) has been changed to match the publication year Nancy (2013) given in the reference list. Please confirm whether this is correct. 
what is drawing, we consider what can drawing do. In this case, we look specifically at what can drawing do as a tool within interdisciplinary dialogue.

As we have noted above, the twentieth century saw an increasing division between drawing practice in fine art and illustration. What is interesting is that we now see drawing returning to qualities and practices before illustration and fine art were separated. Drawing is emerging as a discipline in itself, one that straddles practices and practitioners from different backgrounds. So our interest is not in what distinguishes fine art from illustration, the boundaries between, but more to focus on drawing as a shared area of interest, and what it can do, with benefits to both fields. This reflects the emerging situation in contemporary graphic practices. For example, at the annual Jerwood Drawing Prize in the United Kingdom, one is likely to see a rich variety of traditions, ideas, attitudes, media, graphic languages and hybrids from fine art, architecture fashion and design sitting with equanimity side by side.

\section{Case studies}

To examine these ideas in more depth, what follows is a number of case studies in recent British drawing introducing specific artists' uses of drawing. The focus is on types of depictive and observational drawing that have 'translation' at the core of their aims, methods and approaches. The case studies are the result of research conducted through conversations with the artists and examination of the work at first hand. We will examine a range of drawings, which while they may individually include layered meanings and imagery requiring interpretation, nonetheless share 
qualities designed to reliably record the better to communicate across a generous spectrum of viewers.

The artists we have selected are useful examples of post-disciplinary itinerancy; each sits across or beyond discipline boundaries and they are perhaps less known to the illustration community than, say, Alexander Roob or the examples mentioned above. All have outgrown their training and developed new ideas and relationships to content, audience and their roles as artists. All use graphic methods that owe a debt to illustration. Some artists like Gibbon were trained in illustration and even worked in the print media and now exhibit in fine art. Others like Midgley and Matthews place themselves in entirely new disciplinary contexts such as medicine and oceanography, not to illustrate, but to reflect, respond and contribute to knowledge.

\section{Julia Midgley}

Julia Midgley has a long-standing practice of taking drawing out to work alongside other disciplines in a diverse range of professional environments. This includes television studios, hospitals, archaeological digs and, most recently, alongside the military in a training hospital and rehabilitation centre.

Midgley's approach is driven by deep curiosity and belies an interest in how things work, and what other people do, believing 'workplaces and factories contain much more than you ever imagined' (personal communication). Her drawings are predominantly figurative and representational carried out onsite, often in pencil on sheets of prepared paper. These drawings are founded in sustained and close 
observation encompassing an awareness of the environment and the activities at play within it. Midgley tends to work on sponsored projects that take place over months, enabling sustained working time and immersion in the environment.

Her most recent commission 'War Art and Surgery', in part funded by Arts Council England, was a collaboration between the artist, The Royal College of Surgeons, the Army Medical Services Training Centre and the Defence Medical Rehabilitation Centre at Hedley Court, and was timed to coincide with the centenary of World War 1.

Figure 1: Julia Midgley, W.A.S.043 Rifleman Swinhoe, Defence Medical Rehabilitation Centre, Headley Court (2012), mixed media on paper. CJulia Midgley

The drawings made at Hedley court were made with soldiers recently returned from tours of duty with life-changing injuries. The pencil is light and moves adroitly over the page. Paper is selected from a sheaf of various prepared sheets according to its weight, tooth and tone to find sympathy with the subject. It is this sheet that is carried back to the studio, minimally highlighted with watercolour to become a completed drawing. All drawings exhibited were made directly onsite. 
The drawings are spare and spacious. The aesthetic is calm, serene reflecting the ethos of the rehabilitation environment. There is a palpable lack of drama. They accurately capture medical procedures, equipment and technology, and faithfully represent the myriad medical professions at work there. The drawings also offer empathy with the soldiers; there is a sense of sacrifice, moments of melancholy and feelings of loss; these effects are heightened by the untouched space around the subject. One of the soldiers, a triple amputee, drawn having a prosthetic leg fitted, said, 'Julia's picture looks to me a bit unfinished; and without my leg on, I look a bit unfinished too' (Alberti 2014: 234). These are not simply spare due to a desire for expediency and time constraints; spare-ness is an important tactic for making meaning in the drawing.

The soldiers' responses tell us something of the conditions in which the drawings were made. These drawings are conducted in sensitive and intimate medical situations not normally open to third-party viewing. Midgley recognizes the peculiar importance of drawing in this role. While cameras are considered intrusive and therefore forbidden, drawing preserves the dignity of the patient: it faithfully records but does not sensationalize. As one patient reflects, 'the drawing doesn't invade my privacy; I can keep it' (Alberti 2014: 286). Drawing reconciles the need to preserve the privacy and dignity of the patients while enabling this unseen aspect of war to be made public; as one patient pointedly noted, 'soldiers deaths are in the news, but not what happens to those of us recovering from injuries' (Alberti 2014: 
286). In doing so drawing is able to open up a dialogue about war and its consequences for those whom nations ask to act on our behalf.

\section{Peter Matthews}

Peter Matthews is an early-career British artist whose practice is structured around a desire to better understand the ecology of the sea and our relationship to it. He travels internationally to work in different ocean environments and has recently collaborated with scientists at the Woods Hole Oceanographic Institute in California. He works across painting, video and sculpture but is best known for his drawings that translate the experience of being immersed in the ocean - for instance, those exhibited at the Drawing Center, New York, in 'Sea Marks' (2010).

His drawings are made while he is immersed in the ocean for many hours on end as he tracks tidal patterns, waves and temperature. The drawings are made on sheets of heavy-weight paper, nailed to a purpose-built floating drawing board. He draws with a variety of instruments making marks, some of which become blurred and smudged by the water that inevitably splashes on to the drawing as Matthews is buoyed by the swell and carried by currents as he draws.

He draws events and occurrences such as the passing of sea birds, clouds, flotsam; he measures the passing of time; and he counts waves. His drawing observes the natural environment as it moves and changes. Transcriptions of the movement of the sea are overlaid with detailed observations of flora, fauna and weather, and his 
internal sense experiences of being in the sea. This is a reflexive process; alongside gathering hard data, Matthews is sensing himself as a recording instrument; he measures the cold, his waning strength, tiredness and fluctuating emotional state. He describes his practice as 'Experiencing the observable and observing the experiential' (Katchadourian 2010: 7).

Matthews is synthesizing internal and external sensory experience; he is responding to the facts of the environment, birds, waves and clouds with graphic marks and form. This is then blended with his observations of what it feels like to be in the sea. It is this blending that most vividly translates the information and experience for a viewer, one who has never stood in the Pacific Ocean for eight hours. Drawing enables the transposition from encounter to image.

Scientists at Woods Hole Institute appreciated Mathews' contribution for the way in which it sat alongside their research and because he worked 'in the first person' and directly.

It offers the authenticity of unmediated observation not bound by the scientific restraints essential to their own research. ${ }^{1}$

Mathews is taking drawing to a boundary where drawing has to adapt to new applications. This is an example of pushing drawing to the limits of the paradigm. Asking drawing to adapt, not for boundary-busting reasons but in the hope that it will be able to account for new experience, extends its capacity to capture phenomena. We see parallels with the nineteenth-century examinations of nebula- 
again at the limits of information that is available to human sensing. By placing himself within the events of the ocean and exposing his sensitivities to it, Matthews puts himself into a haptic-sensory relationship that extends drawing's capacity to translate and communicate information across boundaries. While the drawings are suggestive of science in the manner in which they utilize notational conventions of measurement and data collection and are contributory to science, however, their primary significance is developing how we think about and apply drawing alongside other forms of investigation and research.

Figure 2: Peter Matthews, 5 Hours in the Pacific (2007), ink on paper. (P) Peter Matthews.

\section{Jill Gibbon}

A further example is Jill Gibbon's drawings, made at the frontline between civic and military authorities and those that protest against the industrialization of war and weaponry. Posing under various guises, Gibbon gains entry to tightly controlled Arms fairs - for example, DSEI, the Defence \& Security Equipment International, held in London bi-annually. This is one of the world's largest arms fairs where access is strictly monitored by security personnel, admitting only an elite cabal of industry representatives. Using modest means, a notebook and a pen, she draws the 
grotesque spectacles of international arms buyers being wooed and entertained by scantily clad women. She captures both the boozy buyers and cynical marketeers of death and destruction at play with a biting satirical line that draws upon the legacy of Gilray and Rowlandson.

Figure 3: Jill Gibbon, Eurosatory, Paris, Sketchbook 1 (2008), ink on paper. @Jill Gibbon.

Gibbon, like Matthews, goes into challenging, even dangerous environments. The stakes are high; there is possibility of confrontation, political conflict and arrest. From the outset, her practice is investigative and dialogical, designed to address issues and engage debate, to the extent that the drawings are not necessarily seen as 'Art', not specifically designed for exhibition in art galleries, but to be used as instruments in campaigning - for example, as poster images and material for blogs. The analogy to Douglas Adams' Babel Fish is most apt here; Gibbon's drawing bridges directly across from art and illustration to investigative journalism and political activism.

The discretion of the notebook enables Gibbon to document this environment where other journalistic tools would be barred, and as an object, it can be nearly 
invisible and easily hidden. The notebook unlike the camera and the dictaphone does not carry associations of an evidential tool; video and photography are forbidden for fear of how recordings of the event might be used in the media.

The image of a person with a notebook is also part of Gibbon's 'cover'; it symbolizes diligence and alertness; she appears to be an official delegate and discerning buyer, perhaps noting down the specifications of a particular brand of CS gas or the flight management system of a Tomahawk Cruise Missile, while in practice she is recording a spectacle of commerce and power as in the drawing from Eurosatory, Paris, sketchbook 1 (Figure 3).

As with Midgely's access to the military hospitals, drawing is a way in, a means that allows the artist to move into these otherwise unseen or forbidden spaces.

An important feature of Gibbon's drawing practice is the way in which she gathers and translates information, experience ideas and issues. This is not mere documentation:

she uncovers the activities and exchanges capturing it in a mode that is vivid and intentionally provocative. These observations are translated for the viewer into the language of satire, communicating the experience of being inside the arms fair with a visceral and uncomfortable directness. 
In her pen and ink drawings we can identify adaptations and specializations to drawing language that respond to and articulate the subject in a narrative manner. The works are full of urgency, exaggeration, abrupt mark-making and rendered with indelible kinetic marks that capture the fluid dynamics of figures in motion. However, technical innovation is not crucial; her contribution is in re-inventing drawing as an ethical, critical practice.

By interpreting the spectacle before her, noticing manipulations, uncovering symbolism and loaded language, she is interpreting for an audience a 'holistic' sense of what is going on - not a translating machine, but an interpreter. Like an ethnographer or a political scientist she digs below the surface to expose environments and behaviours and goes beyond transcribing and documenting. Her drawing is thus both a tool of transportation, smuggling out the evidence of what has been seen, and of translation, bringing it from one domain into another.

\section{Summary}

So, in each of these artists we see a determination to develop an applied fine art practice, which in the realm of drawing is quite unusual. Each takes drawing outside the studio to operate in an environment that is typically the context of another field. It is in this sense that each is itinerant. 
In many ways some might argue that these practices do not necessarily represent innovation. Drawing was once the primary means of conducting and communicating research. There is a long history of drawing used as a tool of analysis and communication outside fine art, across a spectrum of investigative practices. In Britain alone, prominent examples range across a diverse spectrum of activities from cartography (e.g., Wenceslas Hollar's maps of London), medicine (e.g., William Hunter's anatomical studies), astronomy (William Herschel's studies of nebulae), biology, botany, chemistry (e.g., Robert Hooke's Micrographia, 1685) to documenting the effects and impact of war (e.g., Henry Tonks' surgery drawings, Eric Ravillious' views from fighter planes). The topographical art of Hollar and what we now think of as natural history illustration (e.g., Leonardo Da Vinci) were once intimate, if not conjoined, with painting and print-making, forming part of a continuous practice for artists.

Professionally, the fine arts provided many of the artists who made these scientific representations - for instance, Samuel Hunter (active 1860s), who was employed as an observer on the nineteenth-century Rosse project, an astronomical investigation observatory to study and research nebulae (Nasim 2013: 41).

In the Rosse project and other examples, one of the reasons these drawings are successful is the artists commit themselves absolutely to their subject and yet situate themselves 'to one side' of the event, and in doing so they expose their sensitivities to it. The artist is not pre-empting an outcome or even attempting to communicate at this point; he or she is using drawing to understand and explore a subject, which is 
an act of sensitive, faithful transcription. This is a state of reflection and it is here that the work of the 'Babel Fish' begins. By this we mean that drawing enables the translation of observation and experience into an image that can then be used to communicate the specificity and complexity of the encounter in a direct and coherent manner.

While drawing is more popular than ever, its application as a tool for investigation has fallen by the wayside and is no longer part of the standard model of art education. Even after the advent of photography, John Ruskin argued for the common use of drawing as an instrument for coming to know the world. In the prologue to his The Elements of Drawing Ruskin says that he sees drawing as an instrument for gaining knowledge rather than an end in itself; he writes:

I believe that the sight is a more important thing than the drawing; and I would rather teach drawing that my pupils learn to love Nature, than teach the looking at nature that they may learn to draw. (Ruskin 1997:14) For Ruskin 'sight' meant the capacity to seek and understand, and where he elevates the value of 'sight' over the worth of the artefact - the drawing Ruskin is imploring the artist to engage with the subject above and beyond translating a view into an artwork. (1857)

This ethos is echoed in the writings of the nineteenth-century neurobiologist Santiago Ramon y Cajal. His text, written to advise young researchers Cajal, presents drawing as an essential component of scientific discovery. One reason for this is that 
the act of representing something disciplines and strengthens attention. It forces us to examine the entire phenomenon, thus preventing details that commonly go unnoticed in ordinary observation from escaping our attention (Cajal 1999: 113). Again, it is through drawing that a subject can become more closely known.

The relationship we see between both Ruskin and Cajal's ideas and the drawing discussed in this article is the notion that drawing in the environment requires an artist to put their competencies to the test. In doing so he or she has to be adaptable and inventive, conforming to the restraints and protocols of that particular environment, while also ensuring that the drawing captures the specificities of the encounter. Such drawing, which is a union of scrutiny and sensitivity, achieves a blended language. This is a language that includes observation with the poetics of the encounter, making available to us features and phenomena that we might not otherwise truly see or comprehend.

For Ruskin, the subject was nature as God's work. For the artists we look at, environments and behaviours stand in for God. And they find them in the body and medical investigations, in oceanography and the international trade in weapons. What unites these artists and their ideas is the determination to use drawing as an investigative tool to better understand and communicate the world.

\section{Bridging to the present}


The type of drawing we have identified and highlighted through the case studies arises not as a rebuttal to current ways of working; it does not set out to challenge or replace conceptual or expressive approaches and it is not retrograde or conservative. If we can think of the re-emergence of observational drawing as a 'depictive turn', it is one that sits alongside what we might think of as cutting-edge practices offering complimentary methods that enable different types of investigation and exchange. History provides examples of such relationships; for example, the English artist George Stubbs painting both beloved hunting dogs and the rigorously observed anatomy of the horse. Or, again, the French romantic painter Theodore Rousseau, who in preparation for his luxurious landscapes made drawings so precise and objective that they 'make us forget, conjure away [...]. the artifices of his trade...he falls back on the simple line, modest, anonymous in its unpretentious brevity' (Hughe 1962: 30). In the twentieth century, we see George Grosz's sketchbook of 1950-1957 (Nisbet 1993: 137-38) alternating between the dynamic views of Manhattan skyscrapers and pages of mice caught in traps - one approach painterly and expressive and the other Durer-like in its visionary levels of detail. A recent example can be seen in the work of the contemporary British artist Michael Landy. Following his 2001 installation, Breakdown, a collaborative and relational work in which he constructed an industrial-scale factory process to methodically destroy every one of his 4669 possessions, Landy began 'Nourishment', a long series of drawings and etchings that depicted weeds found around his home in London (2008: 218-51). These seemingly private, small-scale, microscopically and delicately observed studies brought the viewer into intimate relations with the

Comment [K13]: Spelling of author name Huyghe has been changed to name Hughe to match the spelling in the Reference List. Please confirm whether this is correct.

Comment [K14]: Please confirm the accuracy of changes made to the sentence. 
overlooked and unloved within a global city. In their very different ways the two projects explored themes of values and consumption.

For many of the artists and artworks we have selected, context is everything, not simply the site or location of the activity but the new relationships arising out of a meeting of forces internal to them - for example, their training or aesthetic beliefs and the external demands of a particular project or situation. The 'context' then is where, how and, importantly, why the practice of drawing is placed in relation to lived and shared experience. To conceptually and literally re-locate drawing in this way presents challenges, challenges to find a drawing language that is mobile, responsive and capable of insertion into a new setting, perhaps outside ones' comfort zone. To purposefully create or adopt a type of drawing able to gather, examine and communicate phenomena might imply a degree of submissiveness on behalf of the maker, or to condemn the drawing to mere utility. This is not our aim; quite the opposite, an artist and the drawing style with the technical flexibility and determination to confront a banal, difficult or rarely addressed subject can create both artworks of great beauty and significant meaning.

\section{Itinerant drawing and translation}

We have proposed that itinerancy offers opportunities for dialogue, opening up potential for conversations between drawing and other research fields. In each of 
the practices we have highlighted, relationships between drawing and ecology, medicine and activism, respectively, are established. However, what strikes us is that there is not one model for communication, but three. Moreover, and perhaps more significantly, there are multiple types of communication generated through these models.

Matthews' drawing represents a disorderly type of gathering or assembly, Midgley's drawing a form of mediation and documentation, whereas Gibbon's drawing might be compared with editorial journalism in its use of critical tactics such as satire and caricature.

Matthews takes graphic modes, signs and codes from a range of recording and measuring systems. The seismographic line, the contours of a map, isometric bars and the textual-numeric measurement that one may see in an ecologist's notebook are collided together. While this is disorderly, with fragments of mismatched vocabularies, it is a form of blending, of diverse notational practices and of objective observation with subjective immersion.

We use this term blending specifically; it returns us to Ruskin. He values the artist looking at natural phenomena as someone who can synthesize a variety of different impressions both observational and experiential, and in doing so refine their perception. 
He argues that imagination is selective and synthetic and the threads of nature are picked out and then spun together making something stronger forming what he calls 'a garland of thoughts' (Ruskin 1984: 359). He felt that scientists merely transcribe lines and edges, whereas drawing in the hands of the artist is a process of analysis and synthesis, connecting information, thought and ideas.

A key point is that here drawing is not simply translating but interpreting information and experience for an audience. The artists that we are looking at are making a synthesis, one that involves not just innovation in their practice but dialogue and exchange, a bridge between artists and the other.

Julia Midgley's drawing offers an example of another form of bridging, that of between different institutions and between institution and patient. In 'War Art and Surgery', the artist moved between the worlds of the military and medicine observing the requirements of the commission and negotiating the conventions of both professions. She says, 'I have a duty to say what I see and do justice to the organisation' (personal communication). This ability to move freely within these restricted areas was only facilitated by drawing. As noted above, drawing resolved the problem of the camera as it was regarded as sympathetic, unobtrusive and a form of image-making that could be produced with, not of, the patient-soldier as subjects. A further way in which the drawings were instrumental was to open up a space for reflection for patients and medics. We have described above how patients, on looking at the drawings, are able to acknowledge their new challenges, also recognizing the sensitivity of the graphic language in capturing and communicating 
their circumstances (Alberti 2014: 234). Occasionally, her drawings have functioned literally as a mediator between patients and medics; Midgley recalls an instance in her earlier work in hospitals when a relative of a patient used the drawing to communicate with a nurse rather than point to the traumatized body itself. However, the most conventional way in which the drawings communicate is that they tell a story of extraordinary people in extraordinary circumstances and provide a record of a moment in a rapidly advancing medical profession. In the case of 'War Art and Surgery', this is a socio-historical record that would not otherwise be available to the public without the intervention of drawing.

We might regard Jill Gibbon's drawing as a more radical investigative practice. We could even argue that in a literal sense Gibbon does not initiate dialogue. Her drawings are acts of exposure. She shows the public shameful, near illegal, behaviours and activity. She is asking to what degree do you agree with this. This is not dialogue in a diplomatic sense, bringing different fields together into communication to share ideas in the way that Midgley brings together patients and institutions. Gibbon is not a mediator seeking to resolve an ethical problem by bringing parties into discussion. However, her drawings raise powerful issues that provoke responses bridging across art and politics.

\section{Conclusion}

From the examples we have given it is evident that drawing offers a number of modes of communication, and not just communication but translation of information between communities, professions and publics. In doing so each artist 
has sought to adapt their drawing practice to make it useful and beneficial within a wider context.

A further contribution that these innovative contemporary practices make is that they offer a lens through which to revaluate the significance of observational and documentary drawing. This offers a fresh perspective on realist drawing, which enables one to understand historical approaches better. This extends access to a legacy that, as we have demonstrated, remains vital and meaningful today.

The artists we have selected are intent on crossing between disciplines; they are neither exclusively fine artists nor illustrators, and it is their attitude to drawing that is their passport to cross borders. They show little respect to definitions, discipline boundaries or the conventions of media, and they willingly work across a number of artistic fields, contexts and conceptual environments. While hybridity in disciplines is commonplace in the arts, what is interesting here is the role that drawing plays at the heart of this itinerant approach.

Furthermore, itinerant practices such as these demonstrate how drawing as a practice is reflexive, initiating dialogue with itself, with its legacy and its future as a medium and mode of enquiry. This is drawing as a recursive instrument, able to reach forward, be innovative and also reach back into its history, to pick up methods and approaches to be retooled for contemporary use. 
The artists we have discussed are all putting drawing into challenging and difficult situations to test drawing, to better understand what it might be able to do. For some this means taking drawing to the limits of what we may normally think of as its capacity, to the edge of the paradigm, to the edge where its logic and techniques break down. This practice can be seen as one of deconstruction. As familiar methods and processes conceptually and technically fall apart, we become able to reflect back upon drawing's capacity. For others, drawing becomes reimagined as a tool with which to interrogate and understand the world and ultimately communicate this experience with others.

\section{Acknowledgements}

The authors would like to thank Jill Gibbon, Julia Midgley and Peter Matthews for their assistance in the production of this article.

\section{References}

Alberti, S. (ed.) (2014), War, Art and Surgery: The Work of Henry Tonks and Julia Midgley, London: Royal College of Surgeons.

Cajal, S. (1999), Advice for a Young Investigator, Cambridge, MA: MIT Press.
Comment [K16]: Please confirm the accuracy of changes made to the sentence.

Comment [K17]: Please confirm the deletion of JMM. 
Casey, S. and Davies, G. (2012), 'A garland of thoughts: Ruskin and contemporary sight / site sensitive drawing', in TRACEY Drawing and Visualisation Research, Loughborough: TRACEY.

Currie, K. (2007), 'In defence of drawing', in Anita Taylor and Paul Thomas (eds), Drawing Breath, London: Wimbledon College of Art, n.p.

Hoptman, L. (2002), Drawing Now: Eight Propositions, New York: Museum of Modern Art.

Hughe, R. (1962), Art and the Spirit of Man, London: Thames and Hudson.

Katchadourian, N. (2010), Sea Marks, New York: The Drawing Center.

Kingston, A. (2003), What is Drawing? Three Practices Explored: Lucy Gunning, Claude Heath, Rae Smith, London: Blackdog.

Kovats, T. (ed.) (2007), The Drawing Book A Survey of Drawing: The Primary Means of Expression, London: Blackdog. 
Landy, M. (2008), Everything Must Go!, London: Ridinghouse.

Lyons, Lucy (2009), 'Delineating disease: A system for investigating Fibrodysplasia

Ossificans Progressiva', Ph.d. thesis, Sheffield: Sheffield Hallam University.

McCannon, D. (2014), 'Editorial', Journal of Illustration, 1:1, 1 April, pp. 3-8(6),

http://www.ingentaconnect.com/contentone/intellect/jill/2014/00000001/0000000

1/art00001;jsessionid=4fbjbjc2h8a91.alice.

Miller, M. (2013), 'Illustrating space as collaborative, socially engaged practice: The first report from the DRAW DUKE STREET residency', Varoomlab Journal, 2,

Spatialising Illustration, http://www.varoom-mag.com/wp-

content/uploads/2013/11/VaroomLab Journal Issue2.pdf.

Nancy, J. L. (2013), The Pleasure in Drawing, New York: Fordham University Press.

Nasim, O. W. (2013), Observing by Hand Sketching the Nebulae in the Nineteenth

Century, Chicago and London: University of Chicago Press. 
Neville, F. (2015), 'Review: Book: Regeneration! Conversations, drawings, archives and photographs from Robin Hood gardens', Architects' Journal, 242:16, pp. 56-58, http://search.proquest.com/docview/1781525305?accountid=11979.

Nisbet, P. (ed.) (1993), The Sketchbooks of George Grosz, Cambridge, MA: Harvard University Art Museums.

Ruskin, J. (1984), Modern Painters, vol. III, New York: Knopf.

(1997), The Elements of Drawing, New York: Watson-Guptill.

Sawdon, P. and Marshall, R. (2012), Hyperdrawing Beyond the Lines of Contemporary Art, London: IB Taurus.

Taylor, A. and Thomas, P. (eds) (2007), Drawing Breath, London: Wimbledon College of Art. 
Vormittag, L. (2014), 'Making (the) subject matter: Illustration as interactive,

collaborative practice', Journal of Illustration, 1:1, 1 April, pp. 41-67.

\section{Contributor details}

\section{Contact:}

Note

${ }^{1}$ E-mail conversation with the authors, November 2015.
Comment [K21]: Please provide the complete author bio.

Comment [K22]: Please provide

current full institutional postal address (including post/zip code). If you do not have an institutional address then just an e-mail will suffice. Please note that personal addresses are not printed in this journal. 